\title{
A MUSICALIZAÇÃO NA EDUCAÇÃO INFANTIL
}

\author{
Clarice Martins Monteiro de Miranda ${ }^{1}$ \\ Graciane Aniceto da Silva Fonseca ${ }^{2}$ \\ Jocinira Souza Silva ${ }^{3}$ \\ Kely Cristina da Silva ${ }^{4}$ \\ Mirela Nogueira dos Santos ${ }^{5}$ \\ Rosângela Gomes Lopes de Souza ${ }^{6}$ \\ Soraya Boazegevski ${ }^{7}$
}

\begin{abstract}
RESUMO: Este artigo discute a importância da musicalização na educação infantil. Ao realizar um estudo o mesmo aborda, ainda que brevemente, a história da música e reitera as principais contribuições de pesquisadores e professores que defendem o uso da música nas escolas. Sugere, assim, a existência de duas concepções finais que orientam o uso da música nas escolas: uma que sempre atribui uma determinada função ao trabalho com esse tipo de recurso, e a outra, que a educação musical tem uma finalidade própria. Também é importante notar que, apesar da vantagem do ensino de música nas escolas, enfatizada tanto por teóricos quanto por juristas nacionais, esse método tem aparecido nas escolas com menos frequência. Conclui que há uma série de benefícios que trabalhar com música em sala de aula pode ter no desenvolvimento do aluno, independentemente da concepção aplicada, e aponta para mais pesquisas para determinar a teoria por trás dele, acerca do por que os professores de sala de aula trabalham tão pouco com música, classe.
\end{abstract}

Palavras Chaves: Música. Educação infantil. Recurso didático.

ABSTRACT: This article discusses the importance of musicalization in early childhood education. When carrying out a study, it addresses, albeit briefly, the history of music and reiterates the main contributions of researchers and teachers who defend the use of music in schools. Thus, it suggests the existence of two final conceptions that guide the use of music in schools: one that always assigns a certain function to working with this type of resource, and the other, that music education has a purpose of its own. It is also important to note that, despite the advantage of teaching music in schools, emphasized by both theorists and national jurists, this method has appeared in schools less frequently. It concludes that there are a number of benefits that working with music in the classroom can have on student development, regardless of the applied design, and points to more research to determine the theory behind it, as to why classroom teachers work so little with music. class.

Keywords: Music. Child education. Didactic resource.

\footnotetext{
${ }^{1}$ Graduada em Pedagogia pela UNIP - Universidade Paulista, Especialista em Educação Infantil com ênfase em Educação Especial pela UniSerra - Faculdade de Educação de Tangará da Serra.

${ }^{2}$ Graduada em Pedagogia pela Universidade do Estado de Mato Grosso - UNEMAT, Especialista pela Faculdade UNINA em Educação Infantil - Práticas na sala de aula.

${ }^{3}$ Graduada em Pedagogia pela Faculdade Afirmativo, Especialista em Educação Infantil com Ênfase na Educação Especial pelo Instituto INVEST de Educação Consultoria e Assessoria.

${ }^{4}$ Graduada em Artes Visuais pelo Centro Universitário Internacional - UNINTER, Especialista em Ensino de Artes pela Faculdade Única de Ipatinga.

${ }_{5}^{5}$ Graduada em Educação Artística - Habilitação em Música pela Universidade Federal de Mato Grosso - UFMT, Especialista em Atendimento Educacional Especializado - AEE pela Faculdade de Águas Claras.

${ }^{6}$ Graduada em Pedagogia pela Faculdade Afirmativo.

7 Graduada em Pedagogia pela Universidade Federal de Mato Grosso - UFMT, Especialista em Administração da Educação Pública pela Universidade Federal de Mato Grosso - UFMT.
} 


\section{INTRODUÇÃO}

O objetivo geral deste artigo foi verificar as contribuições que a música pode trazer aos alunos da educação infantil. Os objetivos específicos são: conhecer a história da música; investigar quando e os principais motivos do uso da música, confirmar como a música pode contribuir para a educação infantil.

Nesse contexto, surge a seguinte questão: Que benefícios o trabalho com música em sala de aula pode trazer para o desenvolvimento do aluno? Para realizar este estudo, foi utilizada a bibliográfica realizada em livros e periódicos sobre o tema, com o objetivo de responder as questões que motivaram o estudo deste assunto.

\section{DESENVOLVIMENTO}

\section{I Breve histórico}

A música tem grande valor na educação das pessoas desde a Grécia Antiga, como é possível constatar logo abaixo na citação de Cerqueira (2011, p. 74):

Considerava-se que a música desempenhava importante papel para a constituição da virtude da kalo-kagathía (beleza-bondade), que era considerada o bem maior para um cidadão: o sentido do reconhecimento do belo e de escolha do bom, do justo. Vê-se, assim, a existência de uma pedagogia política, calcada nas noções de ética e estética, na qual o ensino musical merecia bastante atenção, como demonstram as recomendações de Platão e Aristóteles.

Aristóteles na educação musical do cidadão grego, defendia que através da música era possível formar o caráter do sujeito, uma vez que existia um determinado tipo de música mais apropriado para cada tipo de pessoa (CERQUEIRA, 1996). Segundo este mesmo autor a música foi considerada um elemento de grande importância, assim como a ginástica tinha no período arcaico grego, bem anterior a outros ensinamentos, tais como: a matemática, a escrita ou a literatura.

$\mathrm{Na}$ escola tradicional, estabelecida no final do período arcaico, ensinavam se ao jovem a música e a ginástica (P1. Criti. 5od). Somente mais tarde foram incorporados outros ensinamentos, que incluíam escrita, literatura e matemática. O menino de condição livre, filho de cidadão, devia frequentar uma escola, pois isso o ajudava a se projetar, quando adulto, na comunidade de cidadãos, conferindo-lhe ao mesmo tempo status e qualificação (CERQUEIRA, 20II, p. 8o).

Para Marinheiro e Pereira (2017, p. 2) essa afirmação aponta que:

$\mathrm{Na}$ Grécia, a educação era centrada na formação do individuo, visando o seu desenvolvimento completo, a fim de atingir seu máximo de virtude, e a música 
era obrigatória e fazia parte de todas as etapas da educação. Eles acreditavam que a música tinha poderes para suavizar costumes e direcionar a formação do caráter.

A valorização da música não aconteceu apenas na Grécia Antiga, mas, também em território brasileiro, através das transformações que aconteceram entre o final do século XIX e no início do século XX que colocaram a educação no centro das reformas, fazendo com que a música, fosse considerada importante na educação dos sujeitos, se tornando elemento de grande preocupação entre músicos e educadores da época.

Para Morila (2016, p. 2): "No início do período republicano no Brasil parecia haver um consenso: a educação musical era importante para o desenvolvimento do país". Obviamente, estamos falando de uma educação musical acontecendo na época, mais preocupada com técnicas de ensino e interpretação de alguma forma do que com objetivos educacionais para o desenvolvimento do aluno.

\begin{abstract}
Cremos que os coros para as escolas modelos, devem ser muito simples, quase populares, porque se trata geralmente de alunos de tenra idade; os da escola normal ao contrário, devem ser mais sérios, não no estilo fugato, quando a letra não comporta, porém no gênero mais variado: - a duas, três e mesmo quatro partes. Convém que se de uma instrução sólida a esses alunos, banindo as composições de pessoas incompetentes; representando mesmo ao governo nesse sentido, pedindo para que as composições que tenham de ser exibidas nessas escolas, sejam aprovadas por uma comissão especial, a fim de evitar-se o descalabro, como tive ocasião presenciar numa das festas últimas (A Música para todos, I898, p. 452 apud MORILA, 2016, p. 3).
\end{abstract}

Diversos métodos de ensino da música foram propostos no início da República sem que houvesse qualquer tipo de consenso acerca da qual seria o mais adequado de ser utilizado no período. Morila (2016, p. 2) diz que a ocorrência de "uma luta por espaços sociais, notadamente na cultura erudita e na cultura escolar".

\title{
2.2 A música na educação infantil
}

Loureiro (2003, p. 13) diz ser bastante comum a utilização da música de modo simplesmente acessória:

É prática comum nas escolas, principalmente nas séries iniciais, ouvir música na entrada e na saída do período escolar, no recreio e ainda, de forma bastante acentuada, nos momentos de festividades que obedecem a um calendário com datas a serem comemoradas pela comunidade escolar [...].

A partir da observação no ambiente escolar, se fez necessária a criação de uma nova ferramenta de auxilio nas aulas de matemática no que diz respeito às quatro operações fundamentais: Pensando nisso, surgiu a proposta do jogo “A música X”, que se apresenta 
com o objetivo de ajudar no desenvolvimento da aprendizagem do aluno nas operações de adição, subtração, multiplicação e divisão. A ferramenta mencionada acima consiste em fichas numeradas abordando problemas contextualizados sobre as operações fundamentais da matemática usando música (SILVA, 2017, p. 3).

[...] inúmeras são as estratégias metodológicas que podem ser utilizadas em sala de aula para aperfeiçoar o ensino e assim fazer com que as informações sejam passadas aos alunos da melhor forma possível. Dentre estas, destacaremos em nosso trabalho as paródias musicais que são um recurso pedagógico que pode ser utilizado no ensino fundamental, médio e também no ensino superior, nas mais diferentes áreas do conhecimento (BARBOSA e colaboradores, 2017, p. 2).

O que os autores acima defendem é que a música seja usada para facilitar a aprendizagem, a fixação dos conteúdos que são trabalhados por outras disciplinas no dia-adia escolar. É importante destacar que essa estratégia não é muito inovadora no âmbito da educação como um todo, haja vista há certa tradição do uso das músicas por muitos cursinhos pré-vestibulares que perceberam que precisavam ajudar seus alunos para absorverem tantos conteúdos ao longo de tão pouco tempo.

A música pode ser usada para promover valores humanos como a interação entre os alunos e a criação de vínculos entre professores e alunos: [...] além de promover valores importantíssimos como a interação e a disciplina nas crianças, a música oportuniza para elas o desenvolvimento perceptivo atrelado ao desabrochar da linguagem (SILVA; MONTEIRO JÚNIOR, 20I7, p. 3).

[...] A música é uma ferramenta que ajuda na formação do individuo desde criança, pois com ela é possível ter acesso ao mundo lúdico, onde a mesma se expressa e cria. De certa forma, a música proporciona uma autonomia, criatividade e a produção de novos olhares à cerca de temas diversos já sabidos (MARINHEIRO; PEREIRA, 2017, p. I).

A música pode proporcionar resultados significativos para os diversos públicos. $\mathrm{Na}$ área pedagógica, permite a aproximar professores e alunos, e estando esses alunos inseridos em um contexto social, sendo vítimas da marginalidade fazendo com que eles superem as dificuldades vividas em seu cotidiano, esta resgata sua dignidade. Nesse aspecto, a música serviu como estratégia de aproximação das autoras desse trabalho com os alunos do $4^{\underline{0}}$ ano que foram alvos dessa pesquisa, substituindo o medo pela amizade, atribuindo a esses alunos valores artístico, estético, cognitivo e emocional (SILVA; ARAÚJO; SENA, 2017, p. 5). 
A música além de facilitar a aprendizagem de conteúdos e da aquisição de valores por parte dos alunos tem quem aponte a música como um excelente recurso para o professor melhorar seu desempenho em sala de aula e, consequentemente, auxiliar na aprendizagem dos alunos.

[...] é importante que as escolas promovam a formação continuada de seus professores para oferecer um ensino de qualidade e atualizado. Os professores precisam ter a oportunidade de saber sobre as melhores formas de promover o ensino e compreender o quanto o trabalho com musicalização infantil é importante para o cognitivo da criança e contribui para que as aulas sejam mais atraentes e atrativas (ANTERO; SOUSA; ANTERO, 2017, p. r).

Avellar (1995) compreende a música como um excelente estimulador de aprendizagem, sendo um importante recurso para o desenvolvimento da leitura de textos e mesmo da elaboração de hipóteses de escrita. O ensino da música na escola desde a mais tenra idade também é apontada por diversos autores (AVELLAR, 1995; WEIGEL, 1988; LOUREIRO, 2003) como um recurso capaz de contribuir com o desenvolvimento da sensibilidade e da afetividade tanto o quanto da cognição das crianças e adolescentes.

A música é um excelente meio de desenvolvimento das habilidades de leitura e escrita, permite que a criança possa usufruir de satisfações imediatas, considera- se que esta pode contribuir ao nível da comunicação verbal e não-verbal, no que diz respeito a aspectos cognitivos, efetivo-emocionais e motores, ao mesmo tempo promove interação e o autoconhecimento. Para facilitar o ensino de algum conteúdo ou para a alfabetização, seja para aproximar professores de alunos, seja para ensinar valores, de uma maneira geral, todos os autores anteriores parecem não conseguir enxergar a música com tendo uma finalidade em si mesma.

A música na Educação Infantil vai além de cantar para a distração de crianças. A música é um importante meio para que estas possam trabalhar sua expressão corporal, já que provoca estímulos, os quais permite que as crianças se expressem através de gestos. A coordenação motora também pode ser explorada através da música, tanto através da motricidade fina como da ampla, pelo simples tocar ou manusear um instrumento, ou pela a dança (SANTOS, 2017, p. 4).

Acerca do ensino de música na escola, Granja (2006) que diz que a música é um conhecimento importante para a vida cotidiana das pessoas e sua formação, o que consequentemente a torna importante também nos programas escolares. 
[...] trabalhar a linguagem musical na escola é uma forma de levar o aluno a respeitar aos mais diferentes ritmos musicais presente nos diversos tipos de cultura com a finalidade de possibilitar ao aluno embasamento suficiente para que ele possa criar e avaliar, com autonomia, suas produções e as de outras pessoas (GRANJA, 2006, MIRANDA, MIRANDA E OLIVEIRA, 2017, p. 2).

Nesse sentido, a apreciação pura e simples da música corresponde a finalidade nesse tipo de ensino do conteúdo música.

[...] pode-se utilizar essa expressão artística musical para incitar o indivíduo a explorar inúmeras possibilidades de sua utilização no meio educacional e na vida. Utilizando cantigas de roda, canções folclóricas e de domínio público, pode-se fazer uma junção de outras linguagens como a dança e o teatro, além das artes visuais na construção desse processo (BEZERRA, 2017, p. 2).

Apesar de toda essa importância, apontada nos Parâmetros Curriculares Nacionais (BRASIL, 2006), na prática a música ainda apresenta pouco valor nas escolas, o que pode ser verificado pela pouca inserção da música na grade curricular das instituições de ensino, pela ausência do ensino sistemático desse conteúdo e de práticas de aprendizagem musical nesse espaço (LOUREIRO, 2008; GRANJA, 2006).

Nos Referenciais Curriculares Nacionais para a Educação Infantil (RCNEI) a música já aparece citada como um recurso de grande importância.

A música é a linguagem que se traduz em formas sonoras capazes de expressar e comunicar sensações, sentimentos e pensamentos, por meio da organização e relacionamento expressivo entre o som e o silêncio. A música está presente em todas as culturas, nas mais diversas situações: festas e comemorações, rituais religiosos, manifestações cívicas, políticas etc. Faz parte da educação desde há muito tempo, sendo que, já na Grécia antiga, era considerada como fundamental para a formação dos futuros cidadãos, ao lado da matemática e da filosofia (BRASIL, 1998, p. 45).

No RCNEI os objetivos do trabalho com a música são os seguintes (BRASIL, I998, p. 55): "ouvir, perceber e discriminar eventos sonoros diversos, fontes sonoras e produções musicais; brincar com a música, imitar, inventar e reproduzir criações musicais” para as crianças de zero a três anos e "explorar e identificar elementos da música para se expressar, interagir com os outros e ampliar seu conhecimento do mundo; perceber e expressar sensações, sentimentos e pensamentos, através de improvisações, composições e interpretações musicais” para crianças de quatro a seis anos.

O trabalho com música deve considerar, portanto, que ela é um meio de expressão e forma de conhecimento acessível aos bebês e crianças, inclusive aquelas que apresentem necessidades especiais. A linguagem musical é excelente 
meio para o desenvolvimento da expressão, do equilíbrio, da auto-estima e autoconhecimento, além de poderoso meio de integração social (RCNEI BRASIL, 1998, p. 49).

O trabalho pedagógico através da música como instrumento de aprendizagem é de suma importância para a educação das crianças, uma vez que favorece a promoção a integração: cognitiva, afetiva, estética, e também a interação e comunicação social entre os seres humanos.

\begin{abstract}
Antes mesmo de se expressarem por meio da linguagem verbal, bebês e crianças são capazes de interagir a partir de outras linguagens (corporal, gestual, musical, plástica, faz-de-conta, entre outras) desde que acompanhadas por parceiros mais experientes. Apoiar a organização em pequenos grupos, estimulando as trocas entre os parceiros; incentivar a brincadeira; dar-lhes tempo para desenvolver temas de trabalho a partir de propostas prévias; oferecer diferentes tipos de materiais em função dos objetivos que se tem em mente; organizar o tempo e o espaço de modo flexível são algumas formas de intervenção que contribuem para o desenvolvimento e a aprendizagem das crianças (Parâmetros Nacionais de Qualidade para a Educação Infantil (BRASL, 2006, p. I6).
\end{abstract}

Esse mesmo documento aponta alguns elementos que devem ser desenvolvidos na Educação infantil e que podem ser facilmente alcançados pelo trabalho com a música:

As crianças precisam ser apoiadas em suas iniciativas espontâneas e incentivadas a: - brincar; - movimentar-se em espaços amplos e ao ar livre; • expressar sentimentos e pensamentos; • desenvolver a imaginação, a curiosidade e a capacidade de expressão; - ampliar permanentemente conhecimentos a respeito do mundo da natureza e da cultura apoiadas por estratégias pedagógicas apropriadas; - diversificar atividades, escolhas e companheiros de interação em creches, pré-escolas e centros de Educação Infantil (BRASIL, 2006, p. 19).

A aprendizagem da música é muito importante, pois o aluno convive com ela desde muito pequeno, e esta interação contribui de forma significativa para o desenvolvimento da linguagem oral e escrita, levando o aluno a desenvolver habilidades e competências necessárias à sua formação e ao seu desenvolvimento.

O trabalho com a música torna o ambiente escolar mais alegre, sociável e agradável, mediante o qual podem ser propiciados momentos nos quais os alunos podem aprender a conviver e respeitar o limite dos outros. Também considera-se que por meio da música as crianças movimentam-se e através do movimento que:

[...] as crianças expressam sentimentos, emoções e pensamentos, ampliando as possibilidades do uso significativo de gestos e posturas corporais. O movimento humano, portanto, é mais do que simples deslocamento do corpo no espaço: constitui-se em uma linguagem que permite às crianças agirem sobre o meio físico e atuarem sobre o ambiente humano, mobilizando as pessoas por meio de seu teor expressivo (BRASIL, 1998, p. I5). 
Ao ensinar a música nas escolas é preciso estar atento para o que o RCNEI aponta. É importante a compreensão de que o uso da música na escola também corresponde a um processo histórico que, como tal, vem mudando no decorrer do tempo.

\begin{abstract}
No dia-a-dia da educação infantil brasileira, a música vem atendendo a propósitos diversos, segundo concepções pedagógicas que vigoraram (ou vigoram) em nosso país no decorrer do tempo. Ainda percebemos fortes resquícios de uma concepção de ensino que utilizou a música - ou, melhor dizendo, a canção - como suporte para a aquisição de conhecimentos gerais, para a formação de hábitos e atitudes, disciplina, condicionamento da rotina, comemorações de datas diversas etc. Os cantos (ou "musiquinhas", como muitos ainda insistem em dizer) eram quase sempre acompanhados de gestos e movimentos que, pela repetição, tornavam-se mecânicos e estereotipados, automatizando o que antes era - ou poderia vir a ser expressivo. A música, nesses contextos, era apenas um meio para atingir objetivos considerados adequados à instrução e à formação infantis (BRITO, 2003, p. 5I).
\end{abstract}

Os Parâmetros Curriculares Nacionais (1998), quanto o Referencial Curricular Nacional para Educação Infantil (2006) trazem referências para a importância da música no desenvolvimento das crianças seja no âmbito da expressão corporal, do autoconhecimento, da autoestima, entre outros.

Segundo Gama e Souza (2017, p. I) a música parece estar demorando em aparecer no trabalho escolar de maneira mais sistematizada, afirmam que: "Embora o ensino da música esteja previsto na legislação como componente curricular a ser garantido no processo formativo desde a educação infantil, isso não vem se efetivando nas escolas". É uma situação que precisa ser melhorada e necessite de investigações nos locais onde a Educação Básica acontece, ou seja, nas instituições de ensino da Educação Infantil, do Ensino Fundamental e do Ensino Médio.

\title{
CONCLUSÃO
}

A música desempenha um papel importante na educação das pessoas. Em termos de importância, há uma série de benefícios que o uso da música em sala de aula pode trazer para o desenvolvimento do aluno: nessa perspectiva pragmática, a música é usada para apoiar a aprendizagem, para apoiar a aprendizagem. Valores, entre outros benefícios, passa por outra dimensão que entende que a própria música é fundamental para permitir o desenvolvimento de sensibilidades ou simplesmente permitir a fruição desses objetos. 
Quanto às concepções de música existentes, pode-se argumentar que, sejam elas mais pragmáticas ou mais críticas, estão em constante processo de mudança e muitas vezes podem coexistir.

Seja qual for o conceito, o trabalho com música em sala de aula não tem se popularizado apesar de algumas literaturas destacarem a importância desse recurso no ensino. Nesse sentido, este artigo mostra a necessidade de mais pesquisas para tentar determinar qual seria o motivo pelo qual os professores trabalham tão pouco com a música em sala de aula.

\section{REFERÊNCIAS}

ANTERO, Anderson Franklin do Rego; SOUSA Eraldo Alves de; ANTERO, Kátia Farias. Formação continuada: a necessidade da musicalização para crianças. In: CONGRESSO NACIONAL DE EDUCAÇÃO. 4., 2017, Campina Grande, Anais... Campina Grande: Editora Realize, 2017. Disponível em: http://www.editorarealize.com.br. Acesso em ro/02/2022.

AVELlAR, R. M. G. O desafio de continuar a alfabetização. São Paulo. J. M. Editora, I995.

BARBOSA, Lenita da Silva e colaboradores. A utilização de paródias musicais como recurso didático no ensino de zoologia. In: CONGRESSO NACIONAL DE EDUCAÇÃO. 4., 2017, Campina Grande, Anais... Campina Grande: Editora Realize, 2017. Disponível em: http://www.editorarealize.com.br. Acesso em io/02/2022.

BEZERRA, Antero Reis. A música no desenvolvimento cognitivo e intelectual de crianças com necessidades especiais (T.O.D.). In: CONGRESSO NACIONAL DE EDUCAÇÃO. 4., 2017, Campina Grande, Anais... Campina Grande: Editora Realize, 2017. Disponível em: http://www.editorarealize.com.br. Acesso em io/02/2022.

BRASIL. Lei número 11.769 , de 18 de agosto de 2008. Disponível em http://www.planalto.gov.br. Acesso em io/02/2022.

. Parâmetros nacionais de qualidade para a Educação Infantil. Brasília: MEC, 2006. v.

I.

Referencial curricular nacional para Educação Infantil. Brasília: MEC, I988, v. 3.

BRITO, Teca Alencar de. Música na educação infantil: propostas para a formação integral da criança. 2ª ed. São Paulo: Peirópolis, 2003. 
CERQUEIRA, Fábio Vergara. Argumentos aristotélicos em favor do ensino musical: Política, VIII. Dissertatio. Revista de Filosofia da UFPEL, Pelotas: v. 3., p. 7o-88, 1996.

. Ética e estética na música grega: a educação e o ideal da kalo-kagathía. Classica (Brasil), Belo Horizonte: v. 24.n. I/2, p. 73-85, 2011.

GAMA, Carolina Nozella; SOUZA, Ednilton Trindade de. Música alegria na escola: a escola pode ensinar as alegrias da música? In: CONGRESSO NACIONAL DE EDUCAÇÃO. 4., 2017, Campina Grande, Anais... Campina Grande: Editora Realize, 2017. Disponível em http://www.editorarealize.com.br. Acesso em io/o2/2022.

LOUREIRO, Alicia Maria Almeida. O ensino de música na educação fundamental. São Paulo: PAPIRUS. 2003.

MARINHEIRO, Diego Emmanuel Aquino; PEREIRA, Auricélia Lopes. Benefícios da implantação da música em sala de aula. In: CONGRESSO NACIONAL DE EDUCAÇÃO. 4., 2017, Campina Grande, Anais... Campina Grande: Editora Realize, 2017. Disponível em http://www.editorarealize.com.br. Acesso em Io/o2/2022.

MIRANDA, Azenaite Maria; MIRANDA, Azenilda Maria; OLIVEIRA, Mônica de Fátima Guedes de. A música como a arte do ensinar e aprender: uma proposta. In: CONGRESSO NACIONAL DE EDUCAÇÃO. 4., 2017, Campina Grande, Anais... Campina Grande: Editora Realize, 2017. Disponível em: http://www.editorarealize.com.br. Acesso em ro/o2/2022.

MORILA, Ailton Pereira. Métodos pioneiros de ensino musical no Brasil: críticas, lutas e rivalidades. Per Musi., Belo Horizonte: UFMG, n.34, p.I-34. 2016.

PEREIRA, Eugênio Tadeu et al. Música e infância no rádio: o programa Serelepe na Rádio UFMG - Educativa. Per Musi, Belo Horizonte, n. 22, p. 150-156, jul./dez. 2010.

SANTOS, Maria Renally Braga dos e colaboradores. A música na Educação Infantil. In: CONGRESSO NACIONAL DE EDUCAÇÃO. 4., 2017, Campina Grande, Anais... Campina Grande: Editora Realize, 2017. Disponível em: http://www.editorarealize.com.br. Acesso em ro/o2/2022.

SEKEFF, M. L. Da música e seus recursos. 2ª ed. São Paulo: Editora UNESP, 2007.

SILVA, Josué Mendes da; MONTEIRO JÚNIOR, Francisco Nairon. A música e sua função (re) organizadora na aquisição da linguagem em crianças na Creche Escola Municipal Tio Roberto em Paulista/PE. In: CONGRESSO NACIONAL DE EDUCAÇÃO. 4., 2017, Campina Grande, Anais... Campina Grande: Editora Realize, 2017. Disponível em http://www.editorarealize.com.br. Acesso em io/o2/2022.

SILVA, Rita de Cássia Angelo; ARAÚJO, Anna Cláudia Chagas de; SENA, Thaísa Salustino de. A música como aliada no processo ensino aprendizagem. In: CONGRESSO NACIONAL DE EDUCAÇÃO. 4., 2017, Campina Grande, Anais... Campina Grande: 
Editora Realize, 2017. Disponível em http://www.editorarealize.com.br. Acesso em Io/02/2022.

SILVA, Rosália Gomes da. Criação do jogo a música " $X$ " no auxílio das aulas de matemática. In: CONGRESSO NACIONAL DE EDUCAÇÃO. 4., 2017, Campina Grande, Anais... Campina Grande: Editora Realize, 2017. Disponível em http://www.editorarealize.com.br. Acesso em ro/o2/2022.

SILVA, Vanessa Poliana Batista da e colaboradores. Paródia musical: instrumento estimulador e facilitador na dinâmica da aprendizagem. In: CONGRESSO NACIONAL DE EDUCAÇÃO. 4., 2017, Campina Grande, Anais... Campina Grande: Editora Realize, 2017. Disponível em http://www.editorarealize.com.br. Acesso em Io/o2/2022.

WEIGEL, A. M. G. Brincando de música: experiências com sons, ritmos, música e movimentos na pré-escola. Porto Alegre: Kuarup, 1988. 